\title{
Source Allocation of Long-Range Asian Dusts Transportation across the Taiwan Strait by Innovative Chemical-Assisted Identification Methods
}

\author{
Yi-Hsiu Jen, ${ }^{1}$ Yi-Chi Liu, ${ }^{1}$ Iau-Ren Ie, ${ }^{1}$ Chung-Shin Yuan, ${ }^{1}$ and Chung-Hsuang Hung ${ }^{2}$ \\ ${ }^{1}$ Institute of Environmental Engineering, National Sun Yat-Sen University, Kaohsiung 80424, Taiwan \\ ${ }^{2}$ Department of Safety, Health and Environmental Engineering, National Kaohsiung First University, Kaohsiung 824, Taiwan
}

Correspondence should be addressed to Chung-Shin Yuan; ycsngi@mail.nsysu.edu.tw

Received 13 June 2014; Accepted 8 August 2014; Published 27 August 2014

Academic Editor: Hesham El-Askary

Copyright (C) 2014 Yi-Hsiu Jen et al. This is an open access article distributed under the Creative Commons Attribution License, which permits unrestricted use, distribution, and reproduction in any medium, provided the original work is properly cited.

\begin{abstract}
This study used the backward trajectory calculation to obtain the transportation routes of Asian dusts and further combined the chemical composition with the enrichment factor (EF) and the grey relational analysis (GR) to identify the potential sources of eighteen Asian dust storm (ADS) events. The results showed that the chemical compositions of atmospheric particles sampled at the Pescadores Islands were very similar to source soils fugitively emitted from Inner Mongolia, which could assist in identifying the source regions of Asian dusts. This study further compared the source allocation of Asian dusts obtained from EF, GR, and backward trajectory, which showed that the source regions of Asian dusts obtained from these three methods were quite similar. The similarity of backward trajectory and GR reached as high as $83.3 \%$. Moreover, the similarity of backward trajectory calculation and EF or GR was up to $77.8 \%$ while that of the GR and EF was up to $83.3 \%$. Overall, these three methods can successfully allocate the source regions of Asian dusts by $66.7 \%$. Moreover, these innovative chemical-assisted methods can be successfully applied to identify the source regions of Asian dusts for 18 ADS events.
\end{abstract}

\section{Introduction}

At the beginning (February-May) of each year, Asian dusts are frequently blown from hyperarid, arid, and semiarid lands located at Northwest and North China, South Mongolia, and South Siberia [1-3]. For the past half-century, the frequency of Asian dust storms (ADS) occurring in China increased significantly from $0.5\left(1950^{\prime}\right)$ to 14 (2000) times per year, especially the strong and/or super ADS. This phenomenon is correlated mainly to climate change both locally and globally $[4,5]$. It is estimated that approximately 800 million metric tons of sands were emitted to the atmosphere by ADS, which accounts for almost half of natural fugitive sands globally $[6,7]$.

ADS could transport in the upper troposphere easterly to Korea, Japan, and even North America and may also transport southerly to Okinawa, Taiwan, Hong Kong, and Philippine due to anticyclone of atmospheric circulation [811]. Although many sands might be settled down to the ocean and provided nutrients (e.g., $\mathrm{Fe}^{2+}$ ) to the oceanic biosphere, which actually benefits the circulation of global geochemistry, ADS could deteriorate ambient air quality, reduce atmospheric visibility, cause adverse effects on human health, and result in poor scenery and public welfare [12-14]. Additionally, great losses of national economy due to ADS are constantly reported in the West Pacific regions, including crop damage, soil productivity losses, livestock losses, mass migration, human health impacts, and impacts on climate [15-18].

In general, ADS invades Taiwan 2-3 times per year and lasts for about 1-2 days for each invasion. The concentration of suspended particles $\left(\mathrm{PM}_{10}\right)$ in the events of ADS increases approximately 2-3-fold when compared to normal days $[7,19$, 20]. During the ADS periods, significant increases of atmospheric aerosols, particularly $\mathrm{PM}_{10}$, have been frequently observed in Taiwan $[7,8,19,21]$. Particularly, yellow rain episodes have been reported both in Japan and Taiwan at the end of March 2000 [22]. The morphology and apparent color of dust particles filtered from the yellow rain were similar to yellow sands at their source [22]. Furthermore, the results 
obtained from the investigation on source apportioning atmospheric aerosols at an Asian dust episode in metro Kaohsiung indicated that the percentage of fugitive dusts increased significantly from $8.5 \%$ (regular periods) to $26.2 \%$ (Asian dust periods) [23]. Moreover, during the transportation of ADS across continents, the physicochemical characteristics of Asian dusts might be changed by mixing with anthropogenic particles emitted from typical stationary and mobile sources $[24,25]$. Yuan et al. [19] reported that the size distribution of atmospheric aerosols sampled at the Pescadores Islands located in the middle of the Taiwan Strait during the period of ADS switched from bimode to single mode with a peak in coarse particles. Besides, the sulfate $\left(\mathrm{SO}_{4}{ }^{2-}\right)$ and ammonia $\left(\mathrm{NH}_{4}{ }^{+}\right)$of coarse particles $\left(\mathrm{PM}_{2.5-10}\right)$ increase significantly during the period of ADS when compared to non-ADS periods $[7,26,27]$.

In order to investigate the feasibility of chemical-assisted ADS source identification methods which can be used to trace back the soil source regions of ADS, this study compared the transportation routes of ADS event from the backward trajectory calculation to the chemical composition of atmospheric particles and soil sources. Top soils collected in three soil source regions of Inner Mongolia were resuspended and sampled to analyze their chemical composition for further conducting the enrichment factor analysis (EF) and grey relational analysis (GR). Ultimately, this study revealed and discussed the similarity percentages from the backward trajectory calculation, EF, and GR and further obtained the source regions of Asian dusts for $18 \mathrm{ADS}$ events.

\section{Methodologies}

2.1. Sampling Sites of Atmospheric Particles and Soil Dusts. Located at the middle of Taiwan Strait between southeastern China and Taiwan Island, the Pescadores Islands have an area of $127.97 \mathrm{~km}^{2}$, which has the subtropical weather being mainly influenced by East Asian monsoons. During the 18 ADS events, the atmospheric particles were sampled at Hsiaomen site $\left(23^{\circ} 38^{\prime} 471^{\prime \prime} \mathrm{N} ; 119^{\circ} 30^{\prime} 316^{\prime \prime} \mathrm{E}\right)$, which is located at the northwestern coastline of the Pescadores Islands and is approximately $12 \mathrm{~m}$ above the ground and $500 \mathrm{~m}$ and $50 \mathrm{~m}$ far from the coastline and the major roads, respectively. At the sampling sites, this study used to simultaneously collect $\mathrm{PM}_{10}$ (including $\mathrm{PM}_{2.5-10}$ and $\mathrm{PM}_{2.5}$ ) with dichotomous samplers (Anderson, Model Series 241). The sampling flow rate of the sampler was $16.7 \mathrm{~L} / \mathrm{min}$ for a total of 24 hours, and the filters used in this study were $37 \mathrm{~mm}$ quartz filters.

The soil samples were collected from three ADS source regions in the western $\left(38^{\circ} 13^{\prime} 19\right.$ to $39^{\circ} 06^{\prime} 45 \mathrm{~N}$; $115^{\circ} 21^{\prime} 47$ to $\left.116^{\circ} 53^{\prime} 38 \mathrm{E}\right)$, central $\left(40^{\circ} 06^{\prime} 49\right.$ to $41^{\circ} 39^{\prime} 0 \mathrm{~N} ; 110^{\circ} 28^{\prime} 35$ to $\left.111^{\circ} 32^{\prime} 20 \mathrm{E}\right)$, and eastern $\left(43^{\circ} 03^{\prime} 27\right.$ to $43^{\circ} 28^{\prime} 37 \mathrm{~N} ; 116^{\circ} 41^{\prime} 41$ to $\left.119^{\circ} 02^{\prime} 09 \mathrm{E}\right)$ Inner Mongolia, China [7]. Among them, strong winds and dry climate result in serious soil erosion and thus cause heavy ADS frequently (Inner Mongolia Web Site, 2003). A total of thirty soil samples were taken at the top $10-15 \mathrm{~cm}$ surface of open sand lands and were then separately stored in labeled sampling bags. The soil samples were then sent back to the Air Pollution Laboratory at the Institute of Environmental

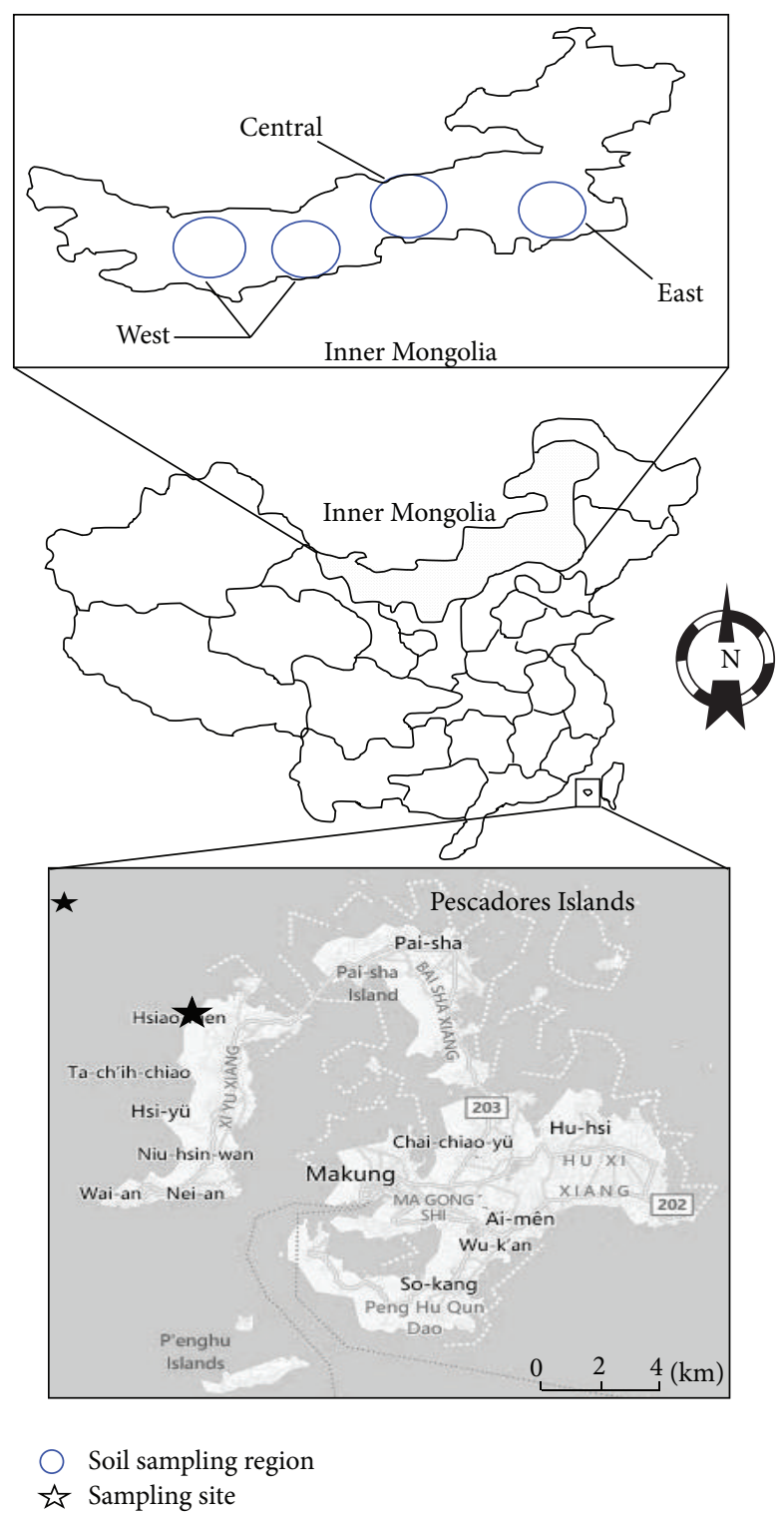

FIgure 1: Location of atmospheric particles $(\star)$ at the Pescadores Islands and soil source regions $(\bigcirc)$ in the Inner Mongolia.

Engineering in National Sun Yat-Sen University, Taiwan, for further chemical analyses. The locations of all soil sampling sites are illustrated in Figure 1.

2.2. Backward Trajectory Calculation. In order to trace the transportation of air parcel, backward trajectories from a specific receptor site were commonly used in this study, which could be used to identify the air mass transportation routes from specific source regions. A hybrid single-particle Lagrangian integrated trajectory (HYSPLIT) has been a widely used model that plots the trajectory of a single air parcel from a specific location and height above ground over a period of time [28, 29]. Backward trajectory calculation used the interpolated measured or modeled meteorological fields to estimate the most likely route over the geographical 


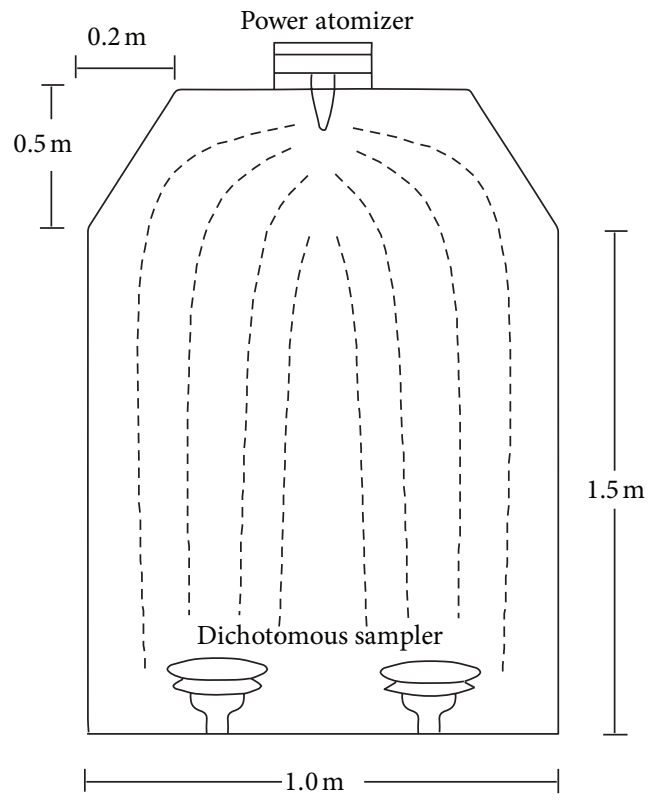

FIGURE 2: Schematic diagram of the resuspension chamber.

areas that provided air parcels from its source to a receptor at a given time. The method essentially follows a parcel of air backward in hourly steps for a specified length of time [10, 30]. Moreover, HYSPLIT uses archived 3-dimensional meteorological fields generated from observations and short-term forecasts. HYSPLIT can be run to generate either forward or backward trajectories using several available meteorological data archives, which is developed by the National Oceanic and Atmospheric Administration's (NOAA) Air Resources Laboratory (ARL). All backward trajectories were drawn at an arrival height of $50 \mathrm{~m}$ above the sea level in this study. By using the NOAA-HYSPLIT model, the dates with high particle concentration at the Pescadores Islands were determined and the transportation routes of air parcels toward the Pescadores Islands during the sampling periods were then simulated. This information was further applied to examine the possible long-range transportation routes conveying ADS from several long-range soil source regions to the Pescadores Islands.

2.3. Enrichment Factor Analysis. Soil samples collected from the eastern, central, and western parts of the Inner Mongolia were sent back to the Air Pollution Laboratory at National Sun Yat-Sen University for further soil resuspension and chemical analyses. The soil samples were resuspended with a dry powder atomizer at the top of a resuspension chamber $\left(2 \mathrm{~m} \times 1 \mathrm{~m}^{2}\right)$, which is illustrated in Figure 2. The resuspended dusts were then sampled as $\mathrm{PM}_{2.5-10}$ and $\mathrm{PM}_{2.5}$ for a total of 0.5 hours by two dichotomous samplers with a total volumetric flow rate of $16.7 \mathrm{~L} / \mathrm{min}$, which was located at the bottom of the resuspension chamber. Particulate matter with diameters larger than $10 \mu \mathrm{m}$ tended to settle down at the bottom of the resuspension chamber. Besides, the resuspended soil dusts were further characterized chemically to apply for the identification of Asian dusts at the downwind sites by using an enrichment factor (EF). The enrichment factor (EF) defined by (1) was used to correlate the downwind atmospheric particles sampled at the Pescadores Islands, Taiwan, to ADS originated from Inner Mongolia, China:

$$
\mathrm{EF}=\frac{(\operatorname{Tr} / \mathrm{Ref})_{\mathrm{PM}}}{(\operatorname{Tr} / \mathrm{Ref})_{\mathrm{crust}}},
$$

where EF is the enrichment factor; $\mathrm{Tr}$ is the trace element; Ref is the reference element; and subscripts PM and crust represents atmospheric particles and crustal soils. Among them, the reference element has to be initially determined. Previous studies reported that the mass ratio of $\mathrm{Mg}, \mathrm{K}$, and $\mathrm{Fe}$ (or $\mathrm{Al}$ ) to $\mathrm{Al}$ (or $\mathrm{Fe}$ ) showed a relatively narrow range for coarse particles, but not for fine particles, which can be used as the fingerprints of Asian dusts originated from the Inner Mongolia [7]. Generally, the enrichment factor close to unity $(\mathrm{EF} \approx 1)$ indicates that the elements consider very high possibility from the specific sources. It is also defined that the elements might come from the specific source when the EF ranged from 0.1 to 10 .

2.4. Grey Relational Analysis. The technique of grey relational analysis is suitable for unascertained problems with poor information [31]. It provides an efficient solution to the uncertainty, multi-input, and discrete data problem. This kind of interaction is mainly through the connection among parameters and some conditions that are already known. Also, it will indicate the relational degree between two sequences with the help of the grey relational analysis. Moreover, the grey relational grade could utilize the discrete measurement method to judge the distance.

When the range of the sequence is too large or the standard value is too enormous, it will cause the influence of some factors to be neglected. Also, in the sequence, if the factors' goals and directions are different, the grey relational analysis might also produce unexpected incorrect results. Therefore, preprocessing of all the data is highly required. This process is called the grey relational generating. An ideal sequence is $x_{0}(k)(k=1,2,3)$ for three responses. The definition of the grey relational grade in the grey relational analysis is to show the relational degree between $n$ sequences $\left(x_{0}(k)\right.$ and $\left.x_{i}(k), i=1,2, \ldots, n ; k=1,2,3, \ldots, n\right)$. The grey relational coefficient $\xi_{i}(k)$ could be calculated by the following equation:

$$
\xi_{i}(k)=\frac{\Delta_{\min }+\zeta \Delta_{\max }}{\Delta_{0 i}(k)+\zeta \Delta_{\max }},
$$

where $\Delta_{0 i}(k)=\left|x_{0}(k)-x_{i}(k)\right|$ is the difference of absolute value between $x_{0}(k)$ and $x_{i}(k)$; $\xi$ is the distinguishing coefficient $(0,1) ; \Delta_{\text {min }}$ is the smallest value of $\Delta_{0 i}(k)$; and $\Delta_{\max }$ is the largest value of $\Delta_{0 i}(k)$. After averaging the grey relational coefficients, the grey relational grade $Y_{i}$ can be obtained as

$$
Y_{i}=\sum_{k=1}^{m} \beta_{k} \xi_{i}(k),
$$

where $m$ is the number of process responses and $\beta_{k}$ is the weight value. 

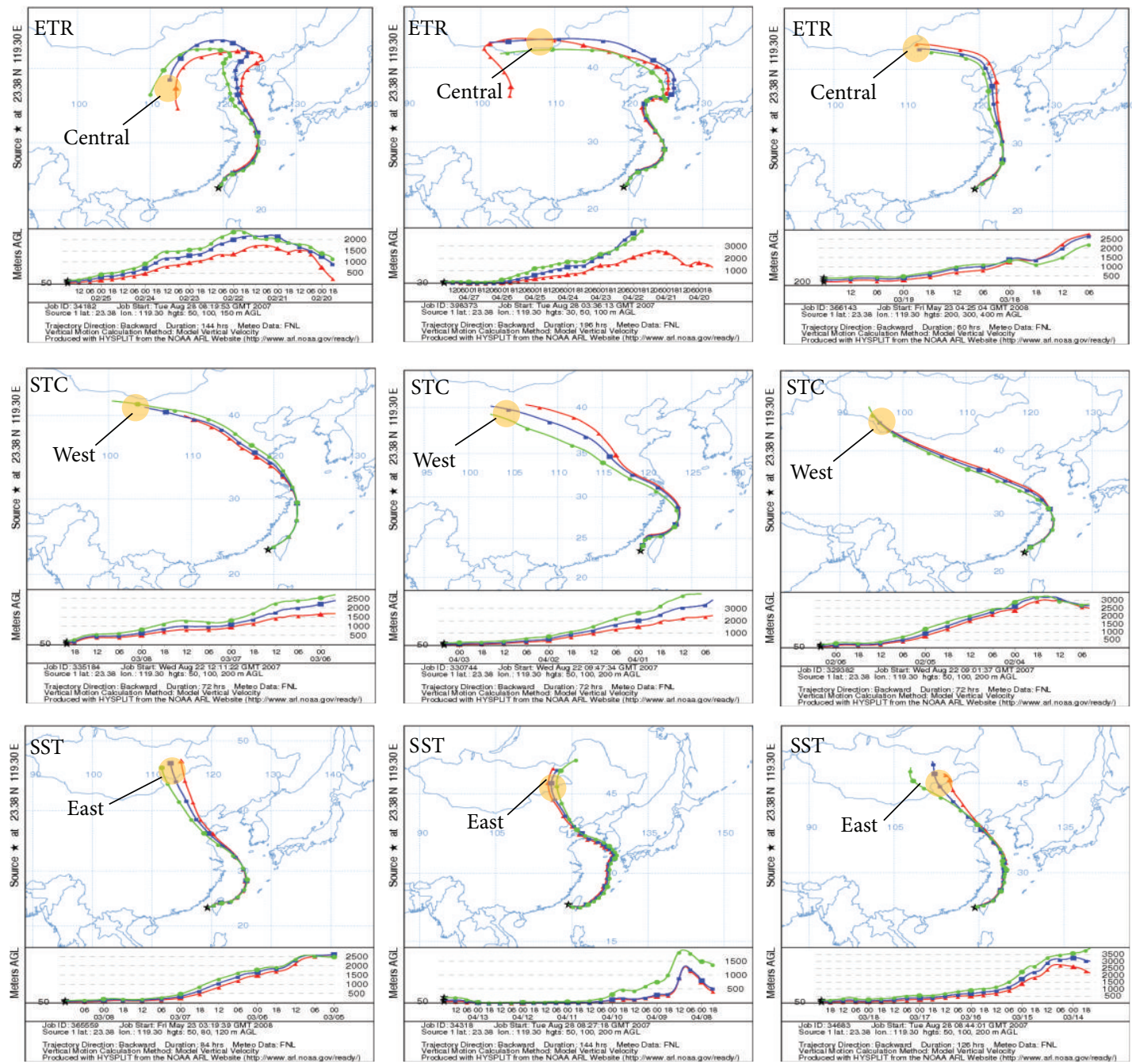

FIGURE 3: Backward trajectories for three types of ADS transportation routes from the Inner Mongolia to the Pescadores Islands.

\section{Results and Discussion}

3.1. Correlation of Chemical Composition with Backward Trajectory Calculation. A total of 18 ADS events were observed at the Pescadores Islands from November 2002 to April 2006. Results obtained from the backward trajectory calculation indicated that three main types of routes dominated the Asian dusts transported from the Inner Mongolia to the Pescadores Islands, which included the eastward transportation and retraced route (ETR), southeastern transportation and circumrotated route (STC), and straight southeastern transportation route (SST), as illustrated in Figure 3.

Table 1 summarizes that the ERT-type ADS events accounted for approximately $33.3 \%$ of the total of 18 ADS events, which were mostly accompanied with strong northeastern monsoons occurring from late February to April. When the ADS transported toward the east, the transportation routes would detour toward the southwest due to atmospheric circulation, which usually passed through the Pescadores Islands. The STC-type ADS events were mainly affected by the strength of the northeastern monsoons mostly observed from November to next April, accounting for about $22.2 \%$ of the total of 18 ADS events. Weakening the northeastern monsoons would result in a smooth curvature of the backward trajectories. The SST-type ADS events occurred mostly from December to next April, in which air parcels transported almost directly from northern China to the Pescadores Islands, Taiwan.

According to the probability of transportation routes, it showed that the SST-type ADS was dominant in all ADS transportation routes, accounting for approximately $44.5 \%$ of the 18 ADS events. The ERT- and STC-type ADS were ordered the second and third routes, respectively. Moreover, this study further aggregated the routes of 18 ADS events and tried to trace them back to their major source regions. All of the ADS routes were transported along the coastline or passed through the major mega cities of North and/or East China, which could alter the chemical composition of atmospheric dusts while transporting from the Inner Mongolia to the Pescadores Islands. During the transportation processes, 
TABLE 1: The transportation types and soil sources of 18 ADS events in this study.

\begin{tabular}{|c|c|c|c|c|}
\hline Transportation route types & Events & Routes probability & Predilection periods & Asian dust source region \\
\hline ETR & & $33.3 \%$ & Late Feb. April & Central (83\%) \\
\hline STC & $n=18$ & $22.2 \%$ & Nov. next April & West (75\%) \\
\hline SST & & $44.5 \%$ & Dec. next April & East $(88 \%)$ \\
\hline
\end{tabular}

(1) ETR is the eastward transportation and retraced route.

(2) STC is the southeastern transportation and circumrotated route.

(3) SST is the straight southeastern transportation route.

Asian dusts would mix with particulate matter emitted from local anthropogenic, industrial, and mobile sources. This study further compared the chemical composition of resuspended source soils and atmospheric dusts for similar transportation route type, as illustrated in Figure 4.

The results indicated that the most abundant chemical composition of source soils were $\mathrm{EC}, \mathrm{SO}_{4}{ }^{2-}, \mathrm{Cl}^{-}, \mathrm{NO}_{3}{ }^{-}, \mathrm{OC}$, and $\mathrm{Ca}^{2+}$ in the eastern source region of Inner Mongolia; EC, $\mathrm{Fe}, \mathrm{Al}, \mathrm{SO}_{4}{ }^{2-}, \mathrm{Ca}$, and $\mathrm{Ca}^{2+}$ were in the central source region; $\mathrm{EC}, \mathrm{SO}_{4}{ }^{2-}, \mathrm{OC}, \mathrm{NO}_{3}{ }^{-}, \mathrm{Cl}^{-}$, and Ca were in the western source region, respectively. On the other hand, the most abundant chemical composition for different transportation routes were $\mathrm{SO}_{4}{ }^{2-}, \mathrm{Ca}^{2+}, \mathrm{NO}_{3}{ }^{-}, \mathrm{Cl}^{-}, \mathrm{Na}^{+}$, and EC for the ERT-type ADS; $\mathrm{SO}_{4}{ }^{2-}, \mathrm{Cl}^{-}, \mathrm{Na}^{+}, \mathrm{NO}_{3}{ }^{-}, \mathrm{Al}$, and Fe for the STC-type ADS; and $\mathrm{SO}_{4}{ }^{2-}, \mathrm{EC}, \mathrm{NO}_{3}^{-}, \mathrm{Na}^{+}, \mathrm{Cl}^{-}$, and $\mathrm{Ca}^{2+}$ for the SSTtype ADS, respectively. The chemical composition between the soils collected in the eastern and western soil sources of Inner Mongolia and Asian dusts sampled at the Pescadores Islands were similar, except the water-soluble $\mathrm{Ca}^{2+}$ and metal $\mathrm{Ca}$. The chemical composition of soils collected at each soil source region was similar but not identical, which could cause the chemical composition variation of atmospheric dusts. Thus, the chemical composition from each soil source was similar to the chemical composition of atmospheric dust on their corresponding transportation route. Among them, the air masses traveled through several major industrial cities of China and transported along the coastal regions by the backward trajectories. Previous studies [29, 30, 32, 33] showed that the chemical proportion on the atmospheric dust was changed by the anthropogenic pollutions or nature sources emission, such as $\mathrm{SO}_{4}{ }^{2-}$ and $\mathrm{NO}_{3}{ }^{-}$originated from direct emissions of major industries (such as petrochemical, power plant, and incinerator) or mobile sources (including onshore and offshore). Calcium and aluminum were dominated by stone processing, construction, and the cement industry. EC was originated primarily from direct emissions of fuel and coal combustion.

This study further compared the chemical composition of the source soils and atmospheric dusts sampled for different transportation routes. The results showed that the chemical fingerprints of the most soil sources and atmospheric dusts were coincided, except some chemical species were different. Actually, the chemical composition of atmospheric dusts could be influenced by the anthropogenic emission sources for different ADS transportation routes, thus resulting in the increase of the portion of $\mathrm{SO}_{4}{ }^{2-}, \mathrm{NO}_{3}{ }^{-}$, and EC. Moreover, Asian dusts could be long-range transported across the ocean to the Pescadores Islands, which could increase the proportion of $\mathrm{Na}^{+}$and $\mathrm{Cl}^{-}$due to oceanic spray. As a whole, the source soils were not exactly the same in their chemical composition between the eastern, central, or western Inner Mongolia, but the chemical species of the source soils in the Inner Mongolia and atmospheric dusts in the Pescadores Islands were similar in the same transportation routes. It could be explained that both backward trajectory calculation and chemical composition can be used to decide the ADS transportation routes concurrently.

\subsection{Correlation of Chemical Composition with Enrichment} Factors and Grey Relational Analysis. The enrichment factor was further applied to identify the ADS source region in the Inner Mongolia toward the Pescadores Islands in this study. During the transportation processes, water-soluble ions and carbonaceous components of Asian dusts could be interfered by the anthropogenic emissions. However, the characteristics of metallic elements are less likely varied in the ambient air. Consequently, this study selected $\mathrm{Al}$ or $\mathrm{Fe}$ as trace metals, which are fairly representative in the earth crust, and can be used to calculate the EF of 15 metals of Asian dusts originated from the Inner Mongolia during the 18 ADS events, as shown in Table 2. The EF values of 15 metal compositions in the range of 0.1 to 10 were shown to be highly relevant, as illustrated in Figure 5. Source identification results showed that $72 \%$ of ADS out of 18 events were originated from the central soil source region of the Inner Mongolia. However, three ADS events (numbers 3, 7, and 8) were not consistently identified for their source regions by using $\mathrm{Al}$ and $\mathrm{Fe}$ as reference elements. The source regions identified by EF values were either the western or the central Inner Mongolia. It might be attributed that Asian dusts could be mixed with other anthropogenic particles during the ADS transportation processes.

This study further applied the grey relational analysis to allocate the source regions of $18 \mathrm{ADS}$ events, as summarized in Table 3. The results indicated that approximately 27,23 , and $50 \%$ of Asian dusts were originated from the eastern, western, and central Inner Mongolia for the 18 ADS events, respectively. Moreover, if the results of grey relational analysis were close to 1 , the soil source of ADS events could be identified with relatively high correlation. Unlike the results of $\mathrm{EF}$ analysis, the source regions would be determined decisively by the grey relational analysis. However, if the grey relational grades of three soil source regions were close to each other, it could be difficult to allocate their 

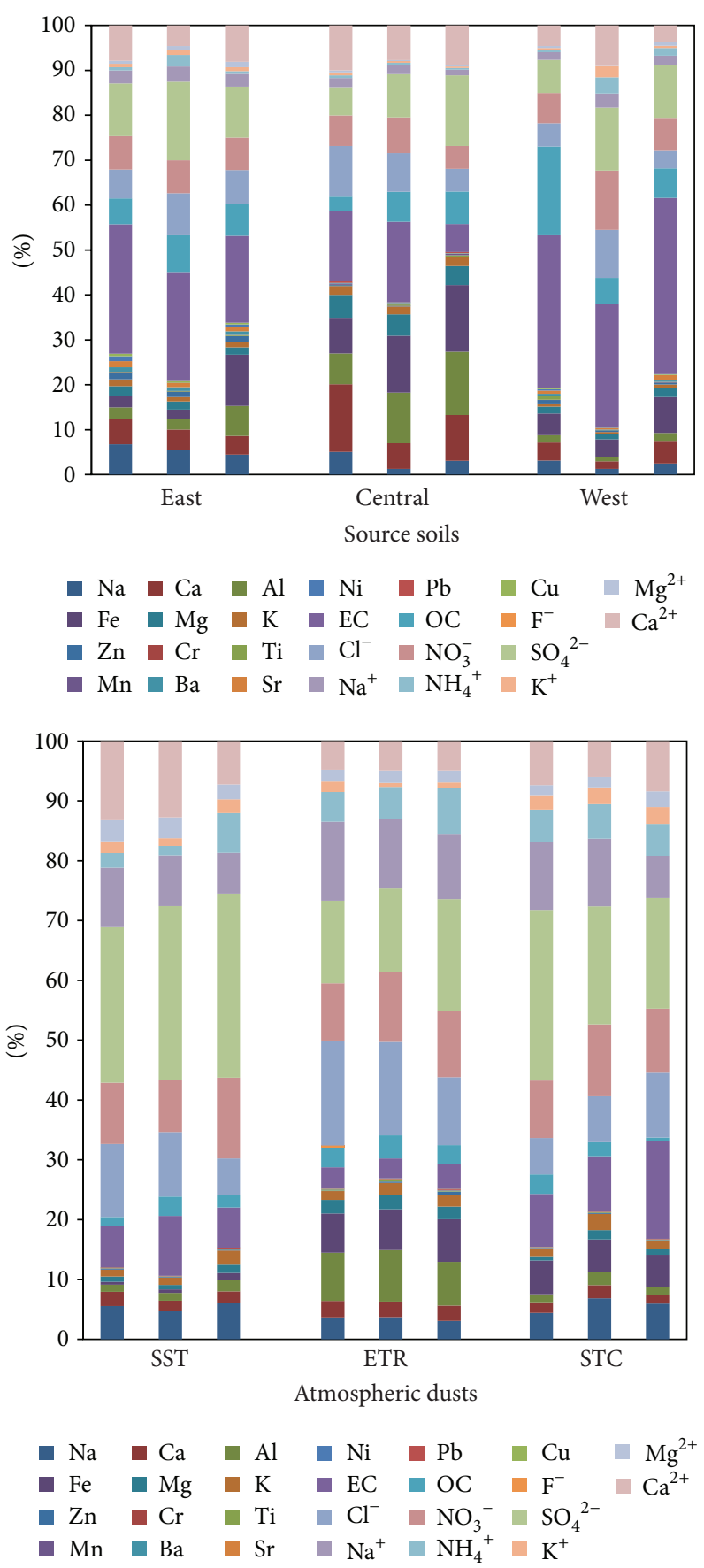

FIGURE 4: Chemical fingerprints of resuspended source soils and atmospheric dusts during the ADS events.

sources in this specific case. For example, number $13 \mathrm{ADS}$ event was identified from the central region of the Inner Mongolia by backward trajectory calculation. Its GR grades were shown as $0.78,0.91$, and 0.89 for the eastern, central, and western soil source regions, respectively. Similar results were obtained from EF analysis, indicating that the chemical composition of Asian dusts played a crucial role in identifying the soil source regions of Asian dusts. Overall, the chemicalbased enrichment factor and the grey relational analysis both showed that the soil source region of number $13 \mathrm{ADS}$ event was highly likely emitted from the central Inner Mongolia.

3.3. Comparison of Three Source Identification Methods. Figure 6 illustrates and compares three methods for identifying the source regions of 18 ADS events. Through the backward trajectory calculation, enrichment factor and grey relational analysis could be applied to identify the ADS events numbers $1,2,6,8,9,11$, and $13-18$, which accounted for $66.7 \%$ of the 
TABLE 2: Source allocation of 18 ADS events in the Inner Mongolia by enrichment factor analysis.

\begin{tabular}{|c|c|c|c|c|c|c|}
\hline \multirow{2}{*}{ ADS events } & \multirow{2}{*}{ Dates of ADS events } & \multirow{2}{*}{ Reference elements } & \multicolumn{3}{|c|}{ ADS source region } & \multirow{2}{*}{ Identified sources } \\
\hline & & & East & Central & West & \\
\hline \multirow{2}{*}{1} & \multirow{2}{*}{ Mar. 8-9, 2002} & $\mathrm{Al}$ & 14 & 9 & 12 & \multirow{2}{*}{ East } \\
\hline & & $\mathrm{Fe}$ & 13 & 9 & 12 & \\
\hline \multirow{2}{*}{2} & \multirow{2}{*}{ Mar. 18-20, 2002} & $\mathrm{Al}$ & 14 & 11 & 13 & \multirow{2}{*}{ East } \\
\hline & & $\mathrm{Fe}$ & 14 & 13 & 13 & \\
\hline \multirow{2}{*}{$3^{*}$} & \multirow{2}{*}{ Mar. 31, 2002} & $\mathrm{Al}$ & 11 & 12 & 13 & \multirow{2}{*}{ West, central } \\
\hline & & $\mathrm{Fe}$ & 11 & 12 & 11 & \\
\hline \multirow{2}{*}{4} & \multirow{2}{*}{ Apr. 13, 2002} & $\mathrm{Al}$ & 7 & 9 & 8 & \multirow{2}{*}{ Central } \\
\hline & & $\mathrm{Fe}$ & 7 & 9 & 7 & \\
\hline \multirow{2}{*}{5} & \multirow{2}{*}{ Apr. 17-19, 2002} & $\mathrm{Al}$ & 11 & 13 & 12 & \multirow{2}{*}{ East } \\
\hline & & $\mathrm{Fe}$ & 11 & 8 & 9 & \\
\hline \multirow{2}{*}{6} & \multirow{2}{*}{ Feb. 25, 2003} & $\mathrm{Al}$ & 12 & 15 & 12 & \multirow{2}{*}{ Central } \\
\hline & & $\mathrm{Fe}$ & 13 & 14 & 12 & \\
\hline \multirow{2}{*}{$7^{*}$} & \multirow{2}{*}{ Mar. 7-8, 2003} & $\mathrm{Al}$ & 12 & 15 & 15 & \multirow{2}{*}{ West, central } \\
\hline & & $\mathrm{Fe}$ & 13 & 13 & 13 & \\
\hline \multirow{2}{*}{$8^{*}$} & Mar 26-27 2003 & $\mathrm{Al}$ & 13 & 15 & 15 & West, central \\
\hline & Mar. 20-27, 2003 & $\mathrm{Fe}$ & 13 & 13 & 13 & vest, central \\
\hline 9 & Apr. 26-27, 2003 & $\mathrm{Al}$ & 12 & 14 & 14 & Central \\
\hline & & $\mathrm{Fe}$ & 12 & 13 & 12 & Central \\
\hline 10 & Feb 6,2004 & $\mathrm{Al}$ & 10 & 12 & 10 & Central \\
\hline & & $\mathrm{Fe}$ & 10 & 12 & 9 & \\
\hline 11 & Feb 15-16 2004 & $\mathrm{Al}$ & 10 & 13 & 10 & Central \\
\hline II & Ге०. 10-10, 2004 & $\mathrm{Fe}$ & 11 & 11 & 11 & Central \\
\hline 12 & Apr. 2, 2004 & $\mathrm{Al}$ & 11 & 13 & 10 & Central \\
\hline 12 & Apr. 2, 2004 & $\mathrm{Fe}$ & 10 & 13 & 11 & Central \\
\hline 13 & Apr 13-15,2004 & $\mathrm{Al}$ & 11 & 14 & 14 & Central \\
\hline & & $\mathrm{Fe}$ & 12 & 14 & 12 & \\
\hline 14 & Nov 292005 & $\mathrm{Al}$ & 12 & 15 & 14 & Central \\
\hline 14 & Nov. 29, 2005 & $\mathrm{Fe}$ & 12 & 15 & 13 & Central \\
\hline 15 & Dec. 21-26, 2005 & $\mathrm{Al}$ & 13 & 14 & 15 & West \\
\hline 15 & Dec. $21-20,2000$ & $\mathrm{Fe}$ & 13 & 11 & 13 & rest \\
\hline 16 & Mar. 14-17, 2006 & $\mathrm{Al}$ & 9 & 13 & 9 & Central \\
\hline 10 & Nar. 14-1/, 2000 & $\mathrm{Fe}$ & 10 & 12 & 12 & Central \\
\hline 17 & Mar. 19,2006 & $\mathrm{Al}$ & 8 & 13 & 8 & Central \\
\hline & Nial. 19, 2000 & $\mathrm{Fe}$ & 8 & 13 & 12 & Central \\
\hline 18 & Apr 24-25,2006 & $\mathrm{Al}$ & 10 & 15 & 10 & East \\
\hline & Apr. $24-25,2000$ & $\mathrm{Fe}$ & 12 & 15 & 12 & East \\
\hline
\end{tabular}

${ }^{*}$ Different source regions determined by $\mathrm{EF}$ values using $\mathrm{Al}$ and Fe as reference elements.

18 ADS events. Comparing backward trajectory calculation with enrichment factor, the similarity percentage was $77.8 \%$ for 18 ADS events, including ADS events numbers 1, 2, 5$9,11,12$, and $14-18$ in this study. In terms of enrichment factor and grey relational analysis, it was shown that they were coincident for $83.3 \%$ of 18 ADS events, including ADS events numbers $1,2,4-6,8-11,12$, and 14-18. In terms of grey relational analysis and backward trajectory calculation, it was shown that they were coincident for $77.8 \%$ of 18 ADS events, including ADS events numbers 1, 2, 4-6, 8-11, and 1418. Generally speaking, the source allocation methods of ADS transported from Inner Mongolia to the Pescadores Islands were relatively accurate, especially for simultaneous application of enrichment factor and grey relational analysis. More importantly, accurate chemical fingerprints of source soils and atmospheric particles are highly required for chemically allocating the source regions of the ADS events.

In order to further confirm the above three optimal methods feasible for allocating the mostly possible sources of ADS events, this study used the past general method to compare with the above three methods, which calculated the mass ratios of $\mathrm{Al}$ and $\mathrm{Sr}(\mathrm{Al} / \mathrm{Sr})$, which had the highest differences in the 15 metals for 18 ADS events. Table 4 lists the mass ratio of $\mathrm{Al} / \mathrm{Sr}$ for resuspended soils collected in the Inner Mongolia 


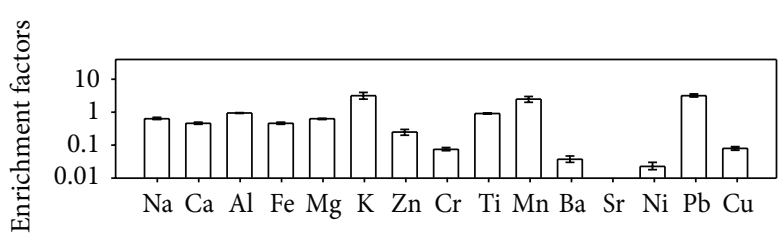

(a1)

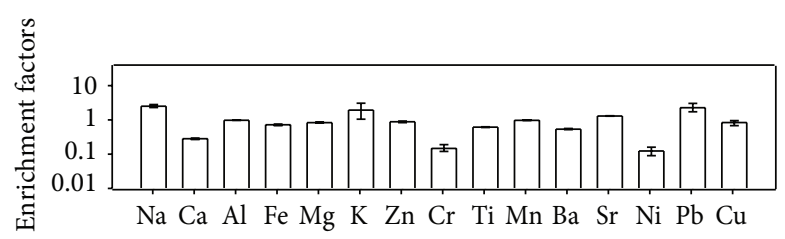

(a2)

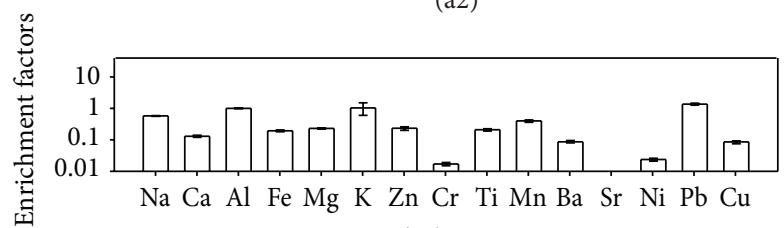

(a)

T $\stackrel{\text { Max }}{\text { Mean }}$

由 $\stackrel{\text { Min }}{\text { Min }}$

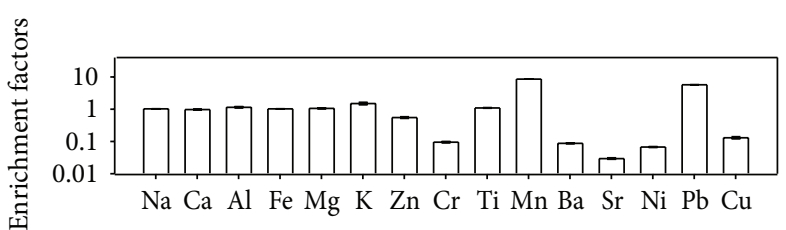

(b1)

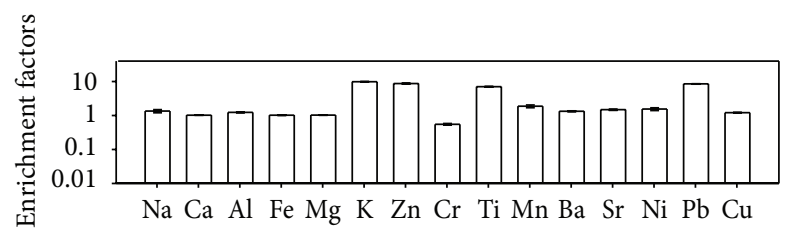

(b2)

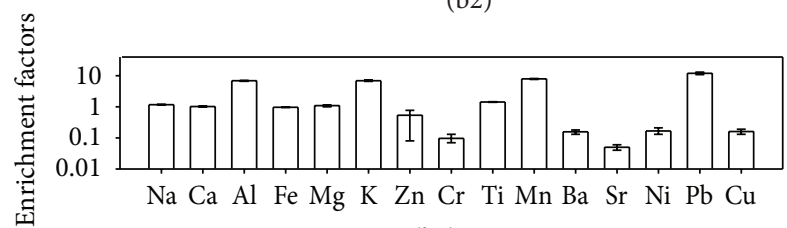

(b3)

向 $\begin{aligned} & \text { Mean } \\ & \text { Min }\end{aligned}$

FIGURE 5: EF values of 15 metals with $\mathrm{Al}$ or Fe as reference elements at the Pescadores Islands. For example, (a1) (a3) are the EF of eastern, central, and western source regions calculated by using aluminum as reference element; (b1) (b3) are the EF of eastern, central, and western source regions calculated by using iron as reference element.

TABLE 3: Source allocation of 18 ADS events in the Inner Mongolia by grey relational calculation.

\begin{tabular}{|c|c|c|c|c|c|}
\hline \multirow{2}{*}{ ADS events } & \multirow{2}{*}{ Dates of ADS events } & \multicolumn{3}{|c|}{ ADS source regions } & \multirow{2}{*}{ Identified sources } \\
\hline & & East & Central & West & \\
\hline 1 & Mar. 8-9, 2002 & 0.90 & 0.87 & 0.82 & East \\
\hline 2 & Mar. 18-20, 2002 & 0.81 & 0.76 & 0.74 & East \\
\hline 3 & Mar. 31, 2002 & 0.79 & 0.84 & 0.87 & West \\
\hline 4 & Apr. 13, 2002 & 0.81 & 0.74 & 0.79 & East \\
\hline 5 & Apr. 17-19, 2002 & 0.79 & 0.78 & 0.71 & East \\
\hline 6 & Feb. 25, 2003 & 0.85 & 0.92 & 0.84 & Central \\
\hline 7 & Mar. 7-8, 2003 & 0.87 & 0.91 & 0.89 & Central \\
\hline 8 & Mar. 26-27, 2003 & 0.78 & 0.91 & 0.83 & Central \\
\hline 9 & Apr. 26-27, 2003 & 0.65 & 0.87 & 0.83 & Central \\
\hline 10 & Feb. 6, 2004 & 0.77 & 0.83 & 0.85 & West \\
\hline 11 & Feb. 15-16, 2004 & 0.70 & 0.84 & 0.78 & Central \\
\hline 12 & Apr. 2, 2004 & 0.83 & 0.86 & 0.93 & West \\
\hline 13 & Apr. 13-15, 2004 & 0.78 & 0.91 & 0.89 & Central \\
\hline 14 & Nov. 29, 2005 & 0.76 & 0.87 & 0.83 & Central \\
\hline 15 & Dec. $21-26,2005$ & 0.72 & 0.78 & 0.89 & West \\
\hline 16 & Mar. 14-17, 2006 & 0.63 & 0.87 & 0.84 & Central \\
\hline 17 & Mar. 19, 2006 & 0.69 & 0.79 & 0.80 & Central \\
\hline 18 & Apr. 24-25, 2006 & 0.92 & 0.89 & 0.83 & East \\
\hline
\end{tabular}




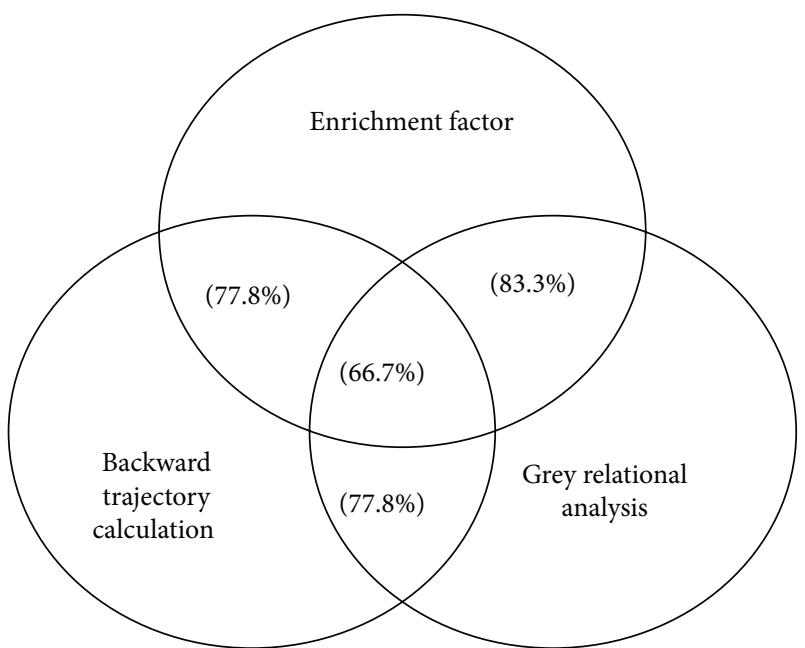

FIGURE 6: Comparison of the correlation percentages among backward trajectory calculation, enrichment factor, and grey relational analysis.

TABLE 4: Comparison of the $\mathrm{Al} / \mathrm{Sr}$ ratios for source soils and atmospheric particles sampled in the Inner Mongolia and at the Pescadores Islands.

\begin{tabular}{lccc}
\hline $\begin{array}{l}\text { Source } \\
\text { regions }\end{array}$ & $\begin{array}{c}\text { Soil samples } \\
\mathrm{Al} / \mathrm{Sr}\end{array}$ & $\begin{array}{c}\text { Dust samples } \\
\mathrm{Al} / \mathrm{Sr}\end{array}$ & $\begin{array}{c}\text { Number of ADS } \\
\text { events }\end{array}$ \\
\hline East & $55.6 \pm 4.3$ & $33.0 \pm 93.3$ & $1,2,4,5,18$ \\
Central & $325.0 \pm 118.0$ & $161.1 \pm 65.1$ & $6-9,11-14,16,17$ \\
West & $2.5 \pm 0.8$ & $132.9 \pm 42.6$ & $7,10,12,15$ \\
\hline
\end{tabular}

and atmospheric particles sampled at the Pescadores Islands. The results showed that the resuspended soil samples in the central Inner Mongolia had relatively higher $\mathrm{Al} / \mathrm{Sr}$ ratio $(325.0 \pm 118.0)$ and observed simultaneously with the higher $\mathrm{Al} / \mathrm{Sr}$ ratio $(161.1 \pm 65.1)$ of atmospheric particles at the Pescadores Islands. Furthermore, the resuspended soils and Asian dusts in the eastern Inner Mongolia both had high relative standard deviation (RSD) of 77 and $283 \%$, respectively. The Al/Sr ratios of the resuspended soils and Asian dusts in the eastern and central Inner Mongolia had their significant characteristics, which could be used to identify the soil source regions of $\mathrm{ADS}$ events, while the $\mathrm{Al} / \mathrm{Sr}$ ratios in the western Inner Mongolia were relatively broad. Overall, although the $\mathrm{Al} / \mathrm{Sr}$ ratio could assist in identifying the sources of ADS, its confidence level was relatively lower than the backward trajectory calculation, enrichment factor, and grey relational analysis. Finally, this study has selected the mostly possible analysis methods to identify the sources of ADS events, which could be used to trace the source areas of ADS event in the future.

\section{Conclusions}

This study successfully combined backward trajectory calculation, enrichment factor, and grey relational analysis to allocate the potential source(s) of 18 ADS events, and identified the transportation routes of Asian dusts transported from the Inner Mongolia to the Pescadores Islands. Three major transportation routes observed for 18 ADS events included ETR, STC, and SST. The variations of chemical components of the atmospheric dusts or source soils were correlated to their transportation routes, in which the chemical characteristics of Asian dusts could be influenced by anthropogenic particles emitted from local stationary and mobile sources during the ADS transportation processes. However, most of chemical components between source soils and atmospheric dusts for the same transportation routes were coincident. Moreover, source identification results showed that $50-72 \%$ out of 18 ADS events were originated from the central region of Inner Mongolia. Comparison of the three methods showed that the chemical-assisted methods demonstrated the accuracy of $66.7 \%$ for identifying the source regions of ADS events. Particularly, simultaneous application of enrichment factor and grey relational analysis raised the accuracy up to 83.3\%. Overall, these three chemical-assisted tracing methods were feasible for identifying the soil source regions of ADC events.

\section{Conflict of Interests}

The authors declare that there is no conflict of interests regarding the publication of this paper.

\section{Acknowledgments}

The authors gratefully acknowledge the financial support from the National Science Council and kind assistance from the Institute of Environmental Engineering at National Sun Yat-Sen University. The authors would like to express their sincere appreciation for its financial and technological support to accomplish this study.

\section{References}

[1] H. Bian, X. Tie, J. Cao, Z. Ying, S. Han, and Y. Xue, "Analysis of a severe dust storm event over China: application of the WRFdust model," Aerosol and Air Quality Research, vol. 11, no. 4, pp. 419-428, 2011.

[2] J. J. Cao, J. C. Chow, J. G. Watson et al., "Size-differentiated source profiles for fugitive dust in the Chinese Loess Plateau," Atmospheric Environment, vol. 42, no. 10, pp. 2261-2275, 2008.

[3] M. T. Cheng, W. C. Chou, C. P. Chio et al., "Compositions and source apportionments of atmospheric aerosol during Asian dust storm and local pollution in central Taiwan," Journal of Atmospheric Chemistry, vol. 61, no. 2, pp. 155-173, 2008.

[4] R. A. Duce, C. K. Unni, B. J. Ray, J. M. Prospero, and J. T. Merrill, "Long-range atmospheric transport of soil dust from Asia to the tropical North Pacific: temporal variability," Science, vol. 209, no. 4464, pp. 1522-1524, 1980.

[5] X. Y. Zhang, S. L. Gong, Z. X. Shen et al., "Characterization of soil dust aerosol in China and its transport and distribution during 2001 ACE-Asia: 1. Network observations," Journal of Geophysical Research D: Atmospheres, vol. 108, no. 9, pp. 42614274, 2003.

[6] X. Y. Zhang, R. Arimoto, and Z. S. An, "Dust emission from Chinese desert sources linked to variations in atmospheric 
circulation," Journal of Geophysical Research D, vol. 102, no. 23, pp. 28041-28047, 1997.

[7] C. S. Yuan, C. X. Hai, and M. Zhao, "Source profiles and fingerprints of fine and coarse sands resuspended from the soils sampled in the central inner mongolia," Particuology, vol. 4, pp. 304-311, 2006.

[8] Y. I. Tsai and C. L. Chen, "Characterization of Asian dust storm and non-Asian dust storm $\mathrm{PM}_{2.5}$ aerosol in southern Taiwan," Atmospheric Environment, vol. 40, no. 25, pp. 4734-4750, 2006.

[9] I. Mori, M. Nishikawa, T. Tanimura, and H. Quan, "Change in size distribution and chemical composition of kosa (Asian dust) aerosol during long-range transport," Atmospheric Environment, vol. 37, no. 30, pp. 4253-4263, 2003.

[10] S. Tan, G. Shi, and H. Wang, "Long-range transport of spring dust storms in Inner Mongolia and impact on the China seas," Atmospheric Environment, vol. 46, pp. 299-308, 2012.

[11] F. Tsai, G. T. J. Chen, T. H. Liu, W. D. Lin, and J. Y. Tu, "Characterizing the transport pathways of Asian dust," Journal of Geophysical Research, vol. 113, Article ID D17311, 2008.

[12] R. D. Brook, "Is air pollution a cause of cardiovascular disease? Updated review and controversies," Reviews on Environmental Health, vol. 22, no. 2, pp. 115-137, 2007.

[13] C. Kang, W. Kim, H. Ko, and S. Hong, "Asian Dust effects on Total Suspended Particulate (TSP) compositions at Gosan in Jeju Island, Korea," Atmospheric Research, vol. 94, no. 2, pp. 345355, 2009.

[14] S. Wang, S. Tsay, N. Lin et al., "First detailed observations of long-range transported dust over the northern South China Sea," Atmospheric Environment, vol. 45, no. 27, pp. 4804-4808, 2011.

[15] M. V. K. Sivakumar, "Impacts of sand storms/dust storms on agriculture," in Natural Disasters and Extreme Events in Agriculture, pp. 159-177, 2005.

[16] D. Y. Jeong, "Socio-economic costs from yellow dust damages in South Korea," Transborder Environmental and Natural Resource Management, pp. 185-198, 2008.

[17] H. Mu, S. Otani, M. Shinoda et al., "Long-term effects of livestock loss caused by dust storm on mongolian inhabitants: a survey 1 year after the dust storm," Yonago Acta Medica, vol. 56, no. 1, pp. 39-42, 2013.

[18] H. Lee, Y. Honda, Y. H. Lim, Y. L. Guo, M. Hashizume, and H. Kim, "Effect of Asian dust storms on mortality in three Asian cities," Atmospheric Environment, vol. 89, pp. 309-317, 2014.

[19] C. S. Yuan, C. C. Sau, M. C. Chen et al., "Mass concentration and size-resolved chemical composition of atmospheric aerosols sampled at the Pescadores Islands during Asian dust storm periods in the years of 2001 and 2002," Terrestrial, Atmospheric and Oceanic Sciences, vol. 15, no. 5, pp. 857-879, 2004.

[20] B. Lee, H. K. Lee, and N. Jun, "Analysis of regional and temporal characteristics of $\mathrm{PM}_{10}$ during an Asian dust episode in Korea," Chemosphere, vol. 63, no. 7, pp. 1106-1115, 2006.

[21] S. Chen, L. Hsieh, M. Kao, W. Lin, K. Huang, and C. Lin, "Characteristics of particles sampled in southern Taiwan during the Asian dust storm periods in 2000 and 2001," Atmospheric Environment, vol. 38, no. 35, pp. 5925-5934, 2004.

[22] C. J. Ma, M. Kasahara, S. Tohno, R. Holler, and T. Kamiya, "Chemical composition of single raindrops fallen in yellow rainfall episode in Japan," in Proceedings of the 2nd Asian Aerosol Conference, pp. 185-186, Pusan, Republic of Korea, 2001.

[23] S. H. Liu and C. S. Yuan, Source apportionment and optical properties of atmospheric aerosols in metro Kaohsiung [M.S. thesis], Institute of Environmental Engineering, National Sun Yat-sen University, Kaohsiung, Taiwan, 2000, (Chinese).

[24] G. McTainsh, Y. Chan, H. McGowan, J. Leys, and K. Tews, “The 23rd October 2002 dust storm in eastern Australia: characteristics and meteorological conditions," Atmospheric Environment, vol. 39, no. 7, pp. 1227-1236, 2005.

[25] Z. X. Shen, J. J. Cao, R. Arimoto et al., "Ionic composition of TSP and PM 2.5 during dust storms and air pollution episodes at Xi'an, China," Atmospheric Environment, vol. 43, pp. 2911-2918, 2009.

[26] T. Nakamura, K. Matsumoto, and M. Uematsu, "Chemical characteristics of aerosols transported from Asia to the East China Sea: An evaluation of anthropogenic combined nitrogen deposition in autumn," Atmospheric Environment, vol. 39, no. 9, pp. 1749-1758, 2005.

[27] R. Zhang, Z. Shen, T. Cheng, M. Zhang, and Y. Liu, "The elemental composition of atmospheric particles at Beijing during Asian dust events in spring 2004," Aerosol and Air Quality Research, vol. 10, no. 1, pp. 67-75, 2010.

[28] S. F. Kong, B. Han, Z. P. Bai, L. Chen, J. W. Shi, and Z. $\mathrm{Xu}$, "Receptor modeling of $\mathrm{PM}_{2.5}, \mathrm{PM}_{10}$ and TSP in different seasons and long-range transport analysis at a coastal site of Tianjin, China," Science of the Total Environment, vol. 408, no. 20, pp. 4681-4694, 2010.

[29] L. Zhu, X. Huang, H. Shi, X. Cai, and Y. Song, "Transport pathways and potential sources of $\mathrm{PM}_{10}$ in Beijing," Atmospheric Environment, vol. 45, no. 3, pp. 594-604, 2011.

[30] H. H. Tsai, C. S. Yuan, C. H. Hung, and Y. C. Lin, "Physicochemical properties of $\mathrm{PM}_{2.5}$ and $\mathrm{PM}_{2.5-10}$ at inland and offshore sites over Southeastern coastal region of Taiwan strait," Aerosol and Air Quality Research, vol. 11, no. 6, pp. 664-678, 2011.

[31] J. L. Deng, A Course on Grey System Theory, HUST Press, Wuhan, China, 1990.

[32] G. Dongarrà, E. Manno, D. Varrica, M. Lombardo, and M. Vultaggio, "Study on ambient concentrations of $\mathrm{PM}_{10}, \mathrm{PM}_{10-2.5}$, $\mathrm{PM}_{2.5}$ and gaseous pollutants: trace elements and chemical speciation of atmospheric particulates," Atmospheric Environment, vol. 44, no. 39, pp. 5244-5257, 2010.

[33] T. C. Li, W. H. Chen, C. S. Yuan, S. P. Wu, and X. H. Wang, "Physicochemical characteristics and source apportionment of atmospheric aerosol particles in Kinmen-Xiamen Airshed," Aerosol and Air Quality Research, vol. 13, no. 1, pp. 308-323, 2013. 

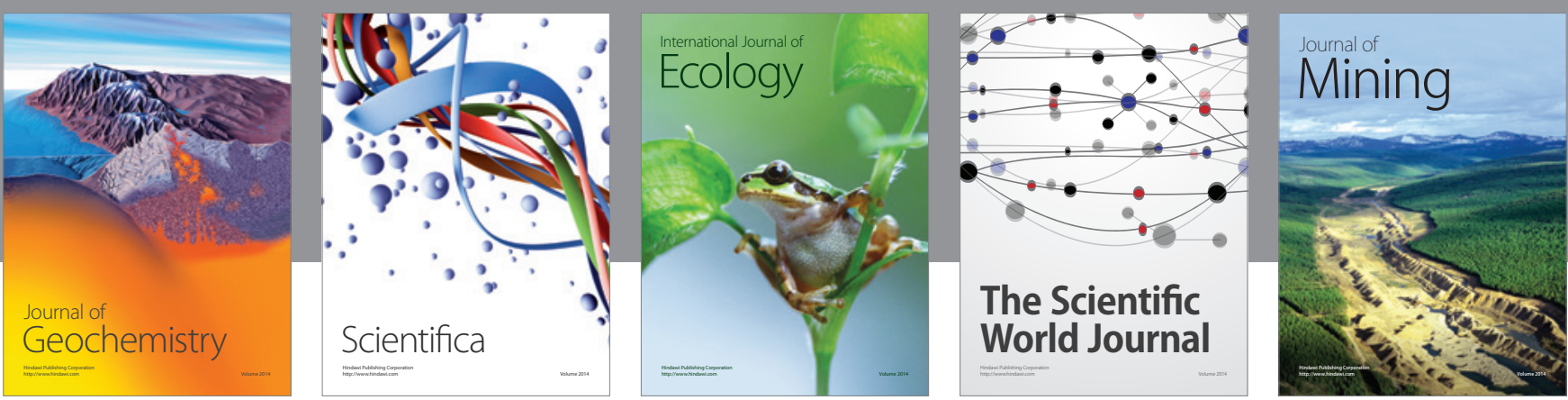

The Scientific World Journal
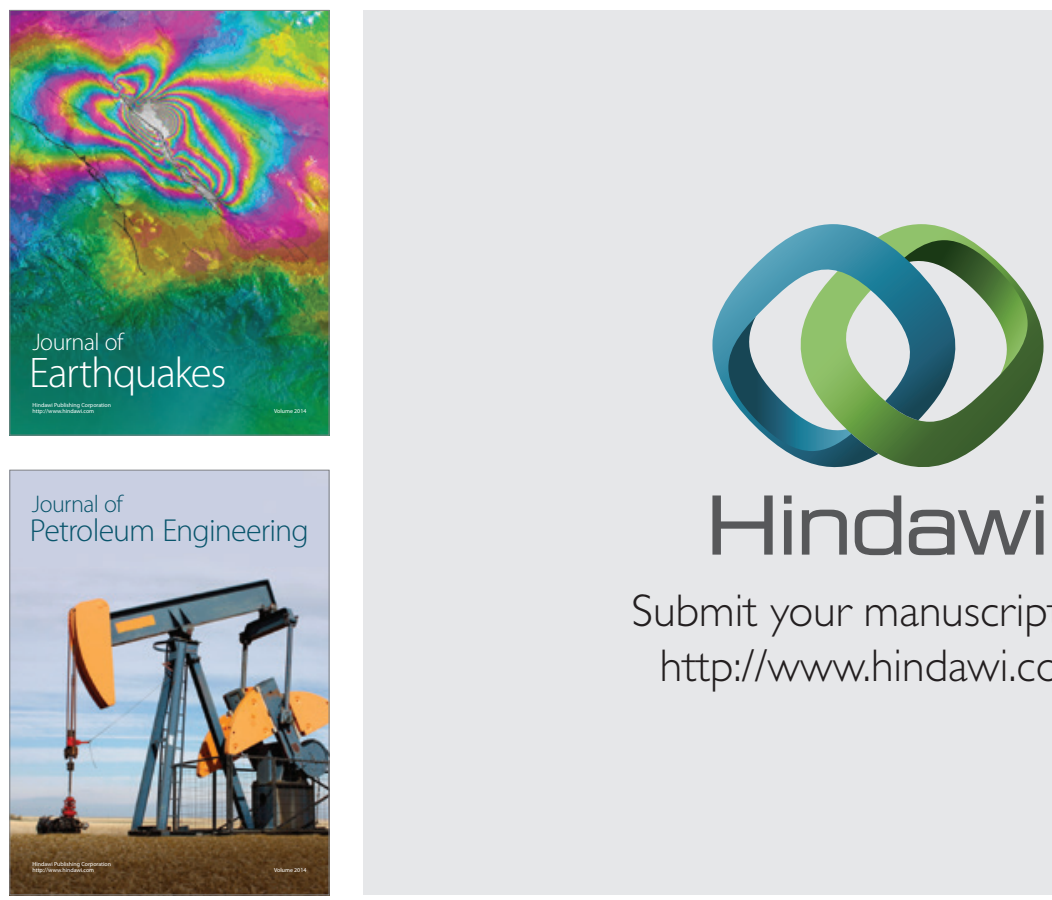

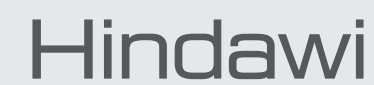

Submit your manuscripts at

http://www.hindawi.com
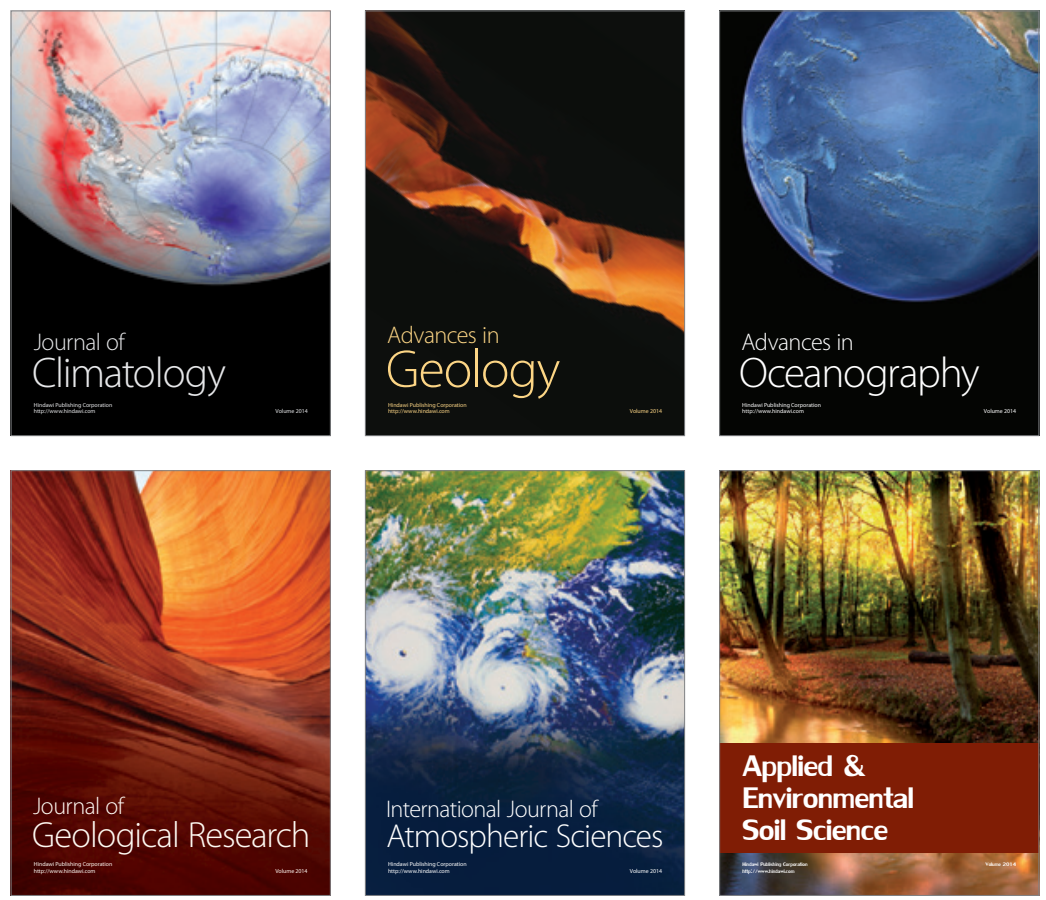
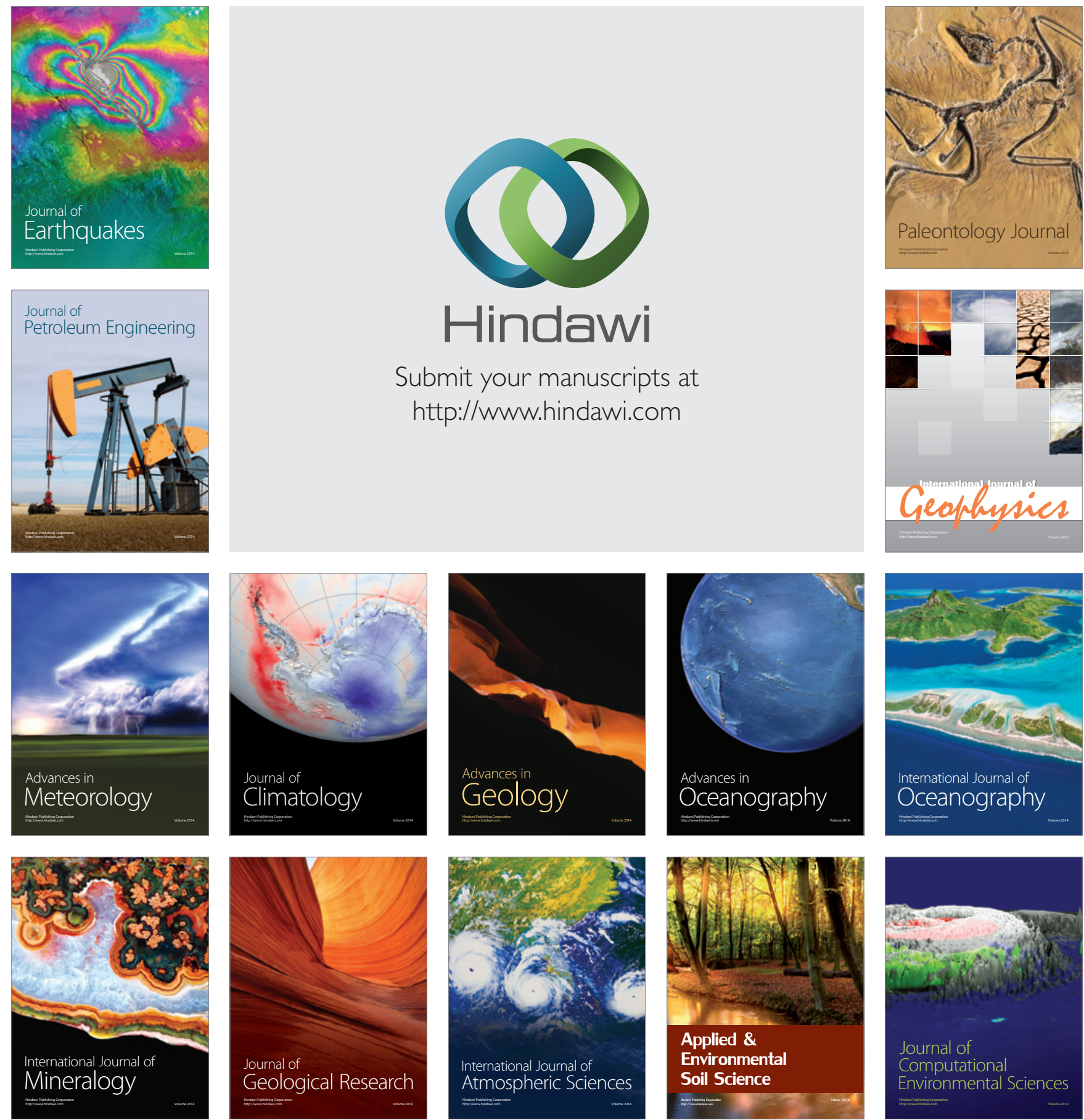